\title{
Принцип Кюри - история становления и перспективы в геологии
}

Левин Б.

Иерусалим, Израиль, levinber@yandex.com

Аннотация. Согласно принципу Кюри, симметрия процесса отражается на симметрии его продукта. Поэтому он может и должен найти широкое применение в геологических исследованиях для восстановления исходных процессов по их вещественным результатам. Его использование в геологии пока еще тормозится недостаточной разработкой его приложений. В статье намечаются пути применения принципа Кюри в сфере геологии.

Ключевые слова: принцип Кюри, симметрия, геологические исследования, предельные виды симметрии, группы Кюри, пьезоэлектрический эффект, фундамент Омолонского массива.

\section{Curie principle - formative history and prospects in geology}

\section{Levin B.}

Israel. Jerusalem, levinber@yandex.com

Annotation. According to Curie principle, the symmetry of a process affects the symmetry of its product. Therefore, it can and should be widely applied in geological studies to determine the original processes by their material results. But using of this principle in geology is still insufficient because weak development of its application. The article outlines the ways to promote the Curie principle to geology.

Key words: Curie principle, symmetry, geological research, threshold types of symmetries, Curie groups, piezoelectric effect, Omolon Massif basement.

\section{Введение}

Глубокое философское обобщение Пьером Кюри (1966) результатов совместного с его братом Жаком открытия и исследований явления пьезоэффекта было не понято его современниками, на что указывал В.И. Вернадский еще в 20-х годах прошлого века (1978, стр. 177), и также подчеркнул А.В. Шубников (1956). Ну и после недолгого его ренессанса в XX веке (40-70-е годы), связанного с именами А.В. Шубникова и И.И. Шафрановского, оно снова ушло в неприятие и недопонимание его научным миром ${ }^{1}$. Достаточно сказать, что рисунок предельных групп симметрии Кюри выставлен сейчас разве что на десятке сайтов и в основном внегеологической тематики (физика, термодинамика, биология). Причем, везде носит чисто иллюстративный характер - просто как дань некоему прошлому. А в печатных геологических изданиях последнее появление этого изображения (не считая данной статьи) имеет, вообще чуть ли не полувековую давность (Шафрановский, Плотников, 1975). Но хоронить философский прорыв Кюри преждевременно. Об этом - данная статья.

\section{Достижения братьев Кюри}

Все началось с того, что Жак и Пьер Кюри задались вопросом об условиях появления разности потенциалов в кристаллах-диэлектриках. Пироэлектрический эффект в кристалле турмалина, т.е. наведение в нем электрического поля при нагревании, был известен давно, но сущность явления оставалась неизвестной. Братья Кюри, отталкиваясь от него, поставили вопрос шире - какие еще воздействия могут вызвать подобные явления, на каких объектах и при каких условиях? В результате глубоких и объемных исследований на приборах, ими же и сконструированных, было открыто явление пьезоэффекта - появление электрического поля в более чем десятке кристаллических веществ при механическом на них воздействии, и выявлены закономерности соотношения кристаллических структур с направлением наведенной разности потенциалов. Таким образом, эти экспериментальные исследования привели к открытию пьезоэлектрического эффекта и глубоким кристал-

\footnotetext{
${ }^{1}$ Похоже, последней работой на эту тему в тот недолгий период признания была статья автора (Левин, 1979)
} 
лографическим разработкам, на которых ныне базируются целые отрасли промышленности многих стран. ${ }^{2}$

\section{Открытия Пьера Кюри}

Затем наступил этап философского осмысления этих практических результатов, и здесь Пьер Кюри совершил прорыв в совершенно неизведанную область, оценить который так и не смогли его современники. Да и в последующих поколениях до этого поднимались только отдельные личности.

Научный прорыв Пьера Кюри состоял из двух самостоятельных, но связанных друг с другом открытий. Первое из них - в области симметрии, и оно раскрывается в трех аспектах: а) понятие «симметрия» Кюри вывел в совершенно новую область - она оказалась присуща не только вещественным объектам (как твердо считали все до того), но также и физическим полям; б) для фиксации этой полевой симметрии в научный обиход было внесено новое понятие - предельная симметрия, т.е. симметрия с бесконечно малыми шагами, и наконец, в) выявлены, описаны и сведены в систему виды этой предельной симметрии.

Спустя время А.В. Шубников (1956) привел эти же виды симметрии Кюри в легко запоминающейся рисуночной форме, расположив их в несколько ином порядке, более соответствующим его, Шубникова, системным разработкам, серьезно продвинувшим понимание всей ситуации (рис. 1). В таком виде они и продолжают фигурировать уже почти 2/3 века. Шубников же дал им и название - предельные точечные группы симметрии. Сейчас, однако, настает необходимость расширить объем всей системы этих понятий и при этом приведенное шубниковское обозначение станет адекватным лишь для части нового объема. Потому далее они будут фигурировать здесь под названиями «виды предельной симметрии» или же просто «группы Кюри».

Второе важнейшее открытие Пьера Кюри - это выявление тесной связи между симметриями причины и ее следствия. Вот эта связь и обозначается ныне как принцип Кюри. Изначально принцип Кюри родился как представление о тесной связи симметрии некоторых определенных кристаллов с симметрией порождаемого ими электрического поля.

Однако, в своем философском обобщении физик Пьер Кюри гениально прозрел возможное (или даже - обязательное) расширение сферы действия данного положения, получившего впоследствии его имя. Явным свидетельством тому является факт, что он в своих формулировках не замыкался на каких-то ограничивающих терминах типа «пьезоэффект», а оперировал максимально расширенным понятием «явление».

Кроме того, это его предвидение ясно выражено им же самим в начальной части своей основополагающей статьи (Кюри, 1966, стр. 96): «Установление различных видов симметрии может быть разбито на два больших раздела соответственно тому, идет ли речь об определении симметрии некоторой ограниченной системы, или системы, которую можно считать неограниченной. Мы здесь займемся только конечными системами». (Выделения мои. БЛ). То есть, он подчеркивает, что в данной статье выводит типы симметрии кристаллов и полей внутри кристаллических тел, но тут же дает и перспективы дальнейшего развития предлагаемой им симметрийной теории на протяженные среды - неограниченные пространства. Видимо, он сам настраивался заняться этим, но сначала его внимание отвлекла злободневная тогда проблема новых радиоактивных элементов, а затем его ранняя трагическая смерть поставила тут долговременную точку.

\section{О последователях, развивавших идею Кюри}

Спустя десятки лет академик А.В. Шубников (1936) ввел понятие кристаллической среды, не имеющей ограничений (в противовес реальному кристаллу, т.е. кристаллическому телу), а затем показал, что симметрия физических свойств кристаллов соответствует именно группам Кюри (Шубников и др., 1940). В 60-х годах профессор И.И. Шафрановский (1968) распространил эти же группы симметрии на маточную среду роста кристаллов, что дало возможность восстанавливать ее ха-

\footnotetext{
${ }^{2}$ Первые эхолоты с пьезодатчиками появились в 1-ю Мировую войну для борьбы с германскими подлодками - это почти через 40 лет после исследований братьев Кюри.
} 
рактер по морфологии минеральных индивидов. И то, и другое были серьезными рывками в развитии и использовании принципа Кюри, но далее это развитие снова замерзло. Вместе с тем, имеются значительные перспективы подхвата и продолжения того прогресса.

Во-первых, следуя логике самого Кюри, нужно развивать учение симметрии для сплошных, неограниченных сред. Они не замыкаются только на поля, физические свойства кристаллов и их маточные среды. В качестве ориентировочной наводки можно назвать, к примеру, состояния среды при формировании магматических или метаморфических объектов. Применяемые в таких ситуациях РТ-диаграммы, не соотносятся с понятиями симметрии, и похоже, что из-за этого упускается важный инструмент генетического анализа.

Простой пример - как указывалось уже выше, группы Кюри в интерпретации Шубникова (рис. 1) хоть и малоприметно, но все же фигурируют на интернет-сайтах ряда наук, однако, скорее как дань авторитету академика, ибо нигде не заметно указаний на конкретное их применение. А в геологии (конкретно - в минералогии) очень редкие статьи лишь используют наработки Шафрановского, и все - дальнейшего продвижения не наблюдается. Вместе с тем предельные группы Кюри, замечательно вписываются в систематику точечных групп кристаллов, и это хорошо подтверждает установку самого Кюри об их наработке для ограниченных тел.

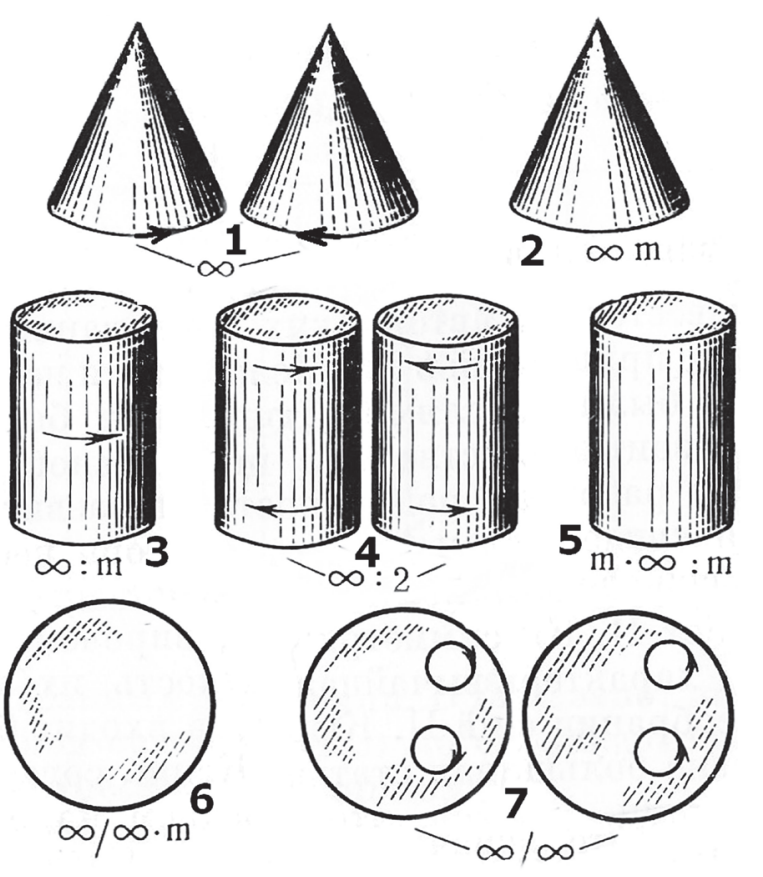

Рис. 1. Предельные точечные группы симметрии.

Взят из статьи А.В. Шубникова (1956) и добавлена оцифровка с названиями: 1 - вращающийся конус; 2 - простой конус; 3 - вращающийся цилиндр; 4 - закрученный цилиндр; 5 - простой цилиндр; 6 - простой шар; 7 - шар с закрученными радиусами-(тензорными).

Fig. 1. Limit point groups of symmetry.

Taken from article A. Shubnikov (1956) and added marks with names: 1 - rotating cone; 2 - simple cone; 3 - rotating cylinder; 4 - twisted cylinder; 5 - simple cylinder; 6 - simple sphere ; 7 - curved sphere (tensor).

\section{Группы Кюри для протяженных сред}

Вопрос о предельных симметриях неограниченных сред, поставленный самим Пьером Кюри, до сих пор оставался в стороне от научного внимания. И вот, первые же попытки подойти к его прояснению приводят к выявлению дополнительных предельных видов симметрии, не отраженных пока что ни на каких схемах.

Например, процесс зонального метаморфизма формирует структуру с явно выраженной плоскостью отражения, делящей посередине его центральную зону. Элемент симметрии - налицо, но в целом вся эта среда, конечно же, не подпадает под привычные кристаллографические формы симметрии, не вписывается она в 32 точечные группы. И точно также она не находит себе аналога в предельных группах Кюри, созданных (стоит еще раз подчеркнуть) с прицелом лишь на ограниченные тела.

В тех предельных группах единичную центральную плоскость симметрии имеют только цилиндры - простой и вращающийся (№№ 5 и 3 на рис. 1), но обе эти фигуры к данной ситуации не 


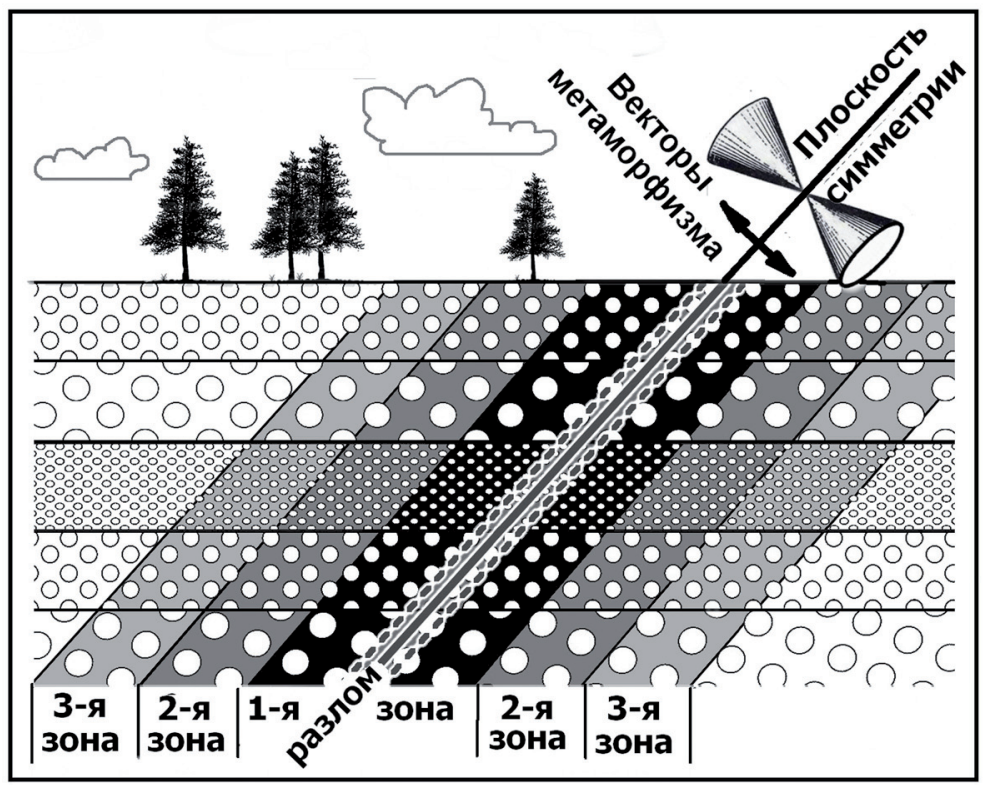

Рис. 2. Схема зонального метаморфизма. Над ней показана группа симметрии этого метаморфизма (двухконусная).

Fig. 2. Zonal metamorphism diagram. The symmetry group of this metamorphism (two-cone) is shown above it.

подходят, ведь здесь мы имеем направленные изменения уровня метаморфизма в обе стороны, т.е. два соосных, разнонаправленных вектора. Направленный вектор в предельных группах отображается простым конусом (там же - № 2), и значит, для случая зонального метаморфизма надо фиксировать новую группу предельной симметрии - два сопряженных конуса, зеркально отражающих друг друга (рис. 2).

Сходная направленность изменений (их векторность) характерна и для контактового метаморфизма, только тут вместо центральной плоскости симметрии имеем магматический объект, и указанные векторы ориентированы по нормалям к его поверхности. При аппроксимации объемного магматического тела в виде шара получаем радиально направленные векторы градиента метаморфизма, т.е. приходим к еще одной новой группе предельной симметрии - шару с векторными радиусами, который отлично вписывается в систему групп Кюри между двумя шарами - простым (со скалярными радиусами) и тензорным (с закрученными радиусами).

Эти же фигуры также выводятся и некоторыми теоретическими построениями, что убедительно свидетельствует об их правомерности в данной логической структуре. Наконец, после их введения общая конфигурация системы видов предельных симметрии неограниченных сред может приобрести вид матрицы.

\section{Принцип Кюри для геологии - два его аспекта}

Протяженные среды, рассмотренные выше, есть результат конкретных геологических процессов. Принцип Кюри, утверждающий взаимозависимость симметрий причины и ее следствия, прямо указывает на возможность, и даже необходимость, его применения в широкой геологической сфере. Этот вопрос и был рассмотрен в первой опубликованной статье на эту тему (Левин, 2018), и несколько затронут в этом сборнике (Левин, 2021). Там путем последовательных логических построений выведена двухаспектная формулировка принципа Кюри для использования его в геологических исследованиях.

Основой для такого переложения стали две позиции. Первая заключается в объединении принципа Кюри с там же введенным принципом Шубникова-Шафрановского, который гласит, что в одном геологическом объекте (не исключая и минеральные индивиды) разные признаки могут подчиняться разным симметриям. ${ }^{3}$ Вторая позиция для некоторого переформатирования принципа Кюри заключается в ясном отличии геологических исследований (или шире - вообее историче-

${ }^{3}$ Объединение тех двух принципов дало основание поименовать получившийся результат как принцип Кюри-ШубниковаШафрановского. Видимо, это было преждевременно, и здесь принцип называется по старому, хоть в него и влито дополнительное представление, доказанное Шубниковым и активно развитое Шафрановским. 
ских) от физических (экспериментальных, лабораторных), на основании которых и сформулирован исходный принцип Кюри. Если химики, физики и вообще экспериментаторы имеют дело с процессами вживую - прямо и непосредственно фиксируют их у себя в лабораториях, то геология такого подарка не получила. Геология имеет дело с некоторыми следами давно прошедших процессов и по ним пытается эти процессы восстановить с той или иной степенью достоверности. Посему при переводе физических положений на рельсы геологии объект и субъект меняются местами.

Вот, исходя из обеих этих операций, окончательный вид принципа Кюри для применения его в геологии принял форму двух взаимодополняющих аспектов:

А) Признаки (части) единого объекта, различающиеся своими симметриями, сформировань разными прочессами, и, значит, сам объект - полигенетичен, образован и преобразован различными процессами, наложенными друг на друга

Б) Если разнородные признаки объекта подчинены одному закону симметрии, то, скорее всего, эти признаки генетически родственны, т. е. сформированы единым процессом.

Ну и понятно, что в обоих аспектах симметрия восстанавливаемого(ваемых) процесса(ов), определяется согласно наблюдаемой симметрии соответствующих признаков.

Формулировки прямо показывают, что аспект А - однозначен, а Б имеет вероятностный характер. Все это детально разьясняется в цитируемой статье, а здесь для дальнейшего надо только подчеркнуть , что вероятность правильности выводов в аспекте Б достаточно велика и сама по себе, да еще резко, экспоненциально растет до почти $100 \%$ при увеличении числа сходных симметрийных признаков исследуемого объекта То же самое можно сказать и при значительной распространенности таких признаков с одинаковой симметрией.

\section{Примеры использования принципа Кюри в геологии}

Разные примеры приложения обоих аспектов принципа Кюри к геологическим (в т.ч. минералогическим) объектам приведены ранее (Левин 2018). Тут будет уточнен один из тех, и рассмотрены другие. Первый аспект (А) проявлен в ситуации с зональным метаморфизмом (рис. 2). Здесь выделяется два типа симметрии - симметрия напластования, отображаемая покоящимся цилиндром с вертикальной осью, и симметрия метаморфических зон с центральной плоскостью отражения. Значит, согласно первому аспекту, они фиксируют два разных процесса, а именно - осадкообразование и метаморфическое воздействие.

Теперь тут стоит детальней разобрать более сложную ситуацию с применением второго аспекта (Б) - ситуацию расшифровки генезиса некоторых комплексов, слагающих фундаменты платформ и срединных массивов. Среди них подчас отмечаются хорошо дифференцированные объекты, по виду как бы расслоенные. Таковые зачастую и относились к первичным осадочным комплексам, затем метаморфизованным на глубине. Именно таким комплексом пачек самой разной мощности сложен Ауланджинский выступ фундамента Омолонского массива (СВ России, Магаданская область). В силу этой «расслоенности», его структура хорошо картируется по выделенным свитам и сериям с приведением в отчетах детальных «послойных» описаний каждого подразделения (Левин, 1991, 2012). И с возможностью прослеживания отдельных пачек на сотни метров и километры.

В дополнение к этому, характерной особенностью пород Ауланджинского выступа является согласное друг с другом положение следующих поверхностей: 1) сланцеватости или гнейсоватости, 2) тонкой полосчатости (до микроскопической), 3) грубой перемежаемости пластов (пачек) различных пород, и 4) картируемых контактов выделяемых толщ, свит, серий. Такие соотношения прослеживаются повсеместно в образованиях, выделенных в легенде к карте-схеме под №№ 3-8 (рис. 3). В предельных видах симметрии каждый из четырех перечисленных параметров аппроксимируется простым цилиндром (рис. 1, № 5) с его осью, совпадающей с нормалью к соответствующей поверхности. Поскольку указанные поверхности согласны друг с другом, то и нормали к ним совпадают, сливаются вместе, а значит, сливаются в один и все четыре цилиндра. Этим полностью доказывается сходство всех четырех симметрий, и отсюда, согласно аспекту Б, много шансов за то, что все эти признаки есть следствия единого для всех них процесса. 


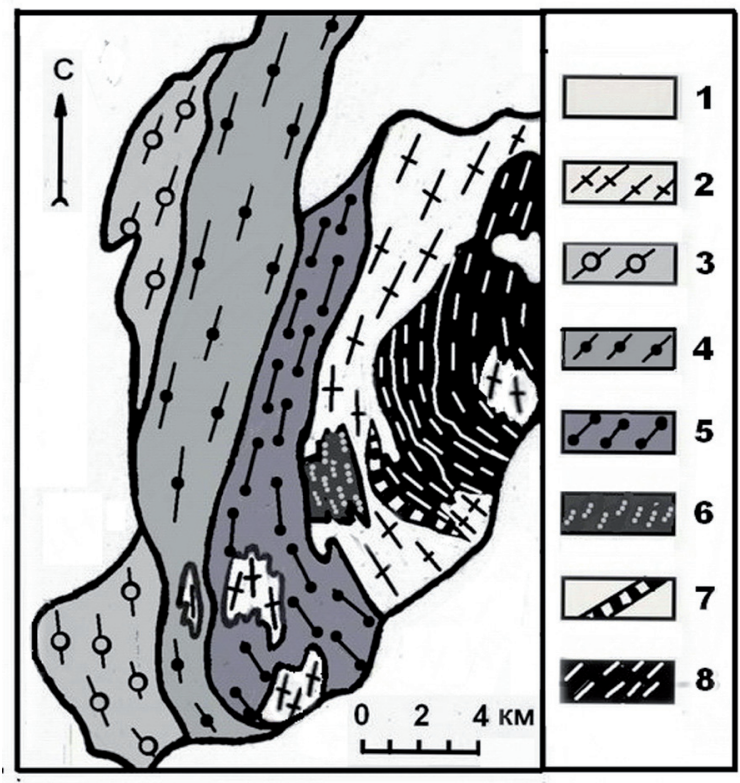

Рис. 3. Геологическое строение Ауланджинского выступа фундамента Омолонского массива (Северо-Восток РФ).

1 - чехол массива (от рифея и выше). 2 - параавтохтонная интрузия биотитовых гранитогнейсов. Приискательская серия фундамента (3-5): 3 - евгеньевская свита, 4 - дождинская свита, 5 - гошинская свита. Золотогорская серия фундамента (6-8): 6 - важенковская свита, 7 - гранатпириболитовая толща, 8 - анюткинская свита в составе трех ее подсвит (разделены сплошными белыми линиями).

Fig. 3 Geological structure (of the Omolon Massif basement within the Aulandjinsky uplift).

1 - The Massif cover (from the Riphean and upwards). 2 - The parautochthonous intrusion of biotite granite-gneisses. The Pri'iskatelsky series of the basement (3-5): 3 - Euguenievsky Formation, 4 - Dozhdinsky Formation, 5 - Goshinsky Formation. The Zolotogorsky series of the basement (6-8): 6-Vazhenkovsky Formation, 7 - Garnet-pyribolite strata, 8 -Anutkinsky Formation (continuous white lines trace herein borders of three discernible subformations).

Далее, поскольку рассланцевание (первая позиция в списке четырех) является продуктом пластического течения в глубоких горизонтах, то и остальные три структурных элемента образованы там же и тогда же - одним и тем же процессом расслоения-рассланцевания. Отсюда и весь комплекс был расслоен изначально на больших глубинах при его кристаллизации из исходной, видимо, однородной и бесструктурной массы.

Остается только разобраться с тем, что аспект Б носит вероятностный характер, т.е. допускает неоднозначность вывода по нему. Когда совпадают симметрии двух признаков, то вероятность их образования одним и тем же процессом, очевидно, уже превышает 50 \%. Наличие трех совпадающих признаков существенно увеличивает эту вероятность, а совпадение четырех симметрий прямо приближает ее к 100 \%. Наконец, распространение данной ситуации повсеместно на всей площади выступа превращает приведенный вывод в практически стопроцентный. Вот так принцип Кюри и дает возможность проведения генетического анализа в геологических исследованиях.

Стоит отметить, что биотитовые гранито-гнейсы (в легенде они - № 2) не рассмотрены здесь вместе с остальными породами Ауланджинского выступа - они выделены в качестве параавтохтонной интрузии, потому что местами фиксируются их структурные несогласия с вмещающими образованиями - отмечены секущие контакты и т.д. То есть, симметрийно они не вписываются в общий фон, и прямо являются иллюстрацией действия пункта А - разносимметрийные признаки говорят о наложении разных процессов.

\section{Заключение}

Принцип Кюри, постулирует тесную связь симметрий причины и следствия, а значит, из него следует близость симметрийных характеристик процесса и его продукта, что должно, по идее, быть востребовано в геологических исследованиях для восстановления прошедших процессов по их вещественным производным. Дело, однако, тормозится слабой разработкой понятийной базы этого принципа, например, его приложений в области протяженных сред. Пьер Кюри, судя по его высказыванию, настраивался когда-нибудь заняться этим вопросом сам, но так не получилось. В статье предложены пути, по которым можно продвинуться вслед за Кюри и его последователями - А.В. Шубниковым и И.И. Шафрановским. Дела тут еще много, может быть, даже очень много, но перспективы благодарные.

\section{Литература}

1. Вернадский В.И. Живое вещество. М. Изд-во: Наука. 1978. С. 360.

2. Кюри П. О симметрии в физических явлениях: симметрия электрического и магнитного полей // Избр. труды. М.-Л. Изд-во: Наука. 1966. С. 95-113. 
3. Левин Б.С. Некоторые аспекты генезиса осадочных и метаморфических пород в свете принципа симметрии Кюри // Системные исследования в геологии. Владивосток. Изд-во: ДВНЦ АН СССР. 1979. С. 76-80.

4. Левин Б.С. Структура метаморфического цоколя юга Омолонского массива // Метаморфические комплексы Северо-Востока СССР, их рудоносность и геологическое картирование. Магадан. 1991. С. $30-45$.

5. Левин Б.С. Архей Омолонского массива. 2012. // http://berlev.info/?p=1378.

6. Левин Б.С. Приложения принципа Кюри в геологии // ЗРМО. 2018. № 6. С. 136-144.

7. Левин Б. О разных подходах к принципу Кюри // Настоящий сборник. 2021.

8. Шафрановский И.И. Лекции по кристалломорфологии. М. Изд-во: Высшая школа. 1968. 174 с.

9. Шафрановский И.И., Плотников Л.М. Симметрия в геологии. Л. Изд-во: Недра. 1975. 144 с.

10. Шубников А.В. Кристалл-индивидуум и кристаллическая среда // Академику В.И. Вернадскому к 50-летию научной и педагогической деятельности. Т. 1. Изд-во: АН СССР. 1936. С. 97-108.

11. Шубников А.В. Симметрия. (Законы симметрии и их применение в науке, технике и прикладном искусстве). М. Изд-во: АН СССР. 1940. 176 с.

12. Шубников А.В. О работах Пьера Кюри в области симметрии // Успехи физ. наук. 1956. № 59. С. $541-602$.

13. Шубников А.В., Флинт Е.Е., Бокий Г.Б. Основы кристаллографии. М.-Л. Изд-во: АН СССР. 1940. 488 с. 